\title{
Estimativa da Área Foliar de Plantas daninhas de Ambiente AQUÁTICO: Eichhornia crassipes ${ }^{1}$
}

\author{
Leaf Area Determination of Aquatic Weeds: Waterhyacinth
}

MARCHI, S.R. ${ }^{2}$ e PITELLI, R.A. ${ }^{3}$

\begin{abstract}
RESUMO - O objetivo deste trabalho foi obter equações que, através de parâmetros lineares dimensionais do limbo e do pecíolo, permitam estimar a área foliar do limbo e a área externa do pulvino de Eichhornia crassipes. Para isso, estudaram-se correlações entre a área foliar real e os parâmetros dimensionais do limbo foliar, como o comprimento ao longo da nervura principal $(C)$ e a largura máxima $(L)$ perpendicular ao eixo principal, assim como correlações entre a área externa real e o comprimento máximo $(C P)$ e o maior diâmetro transversal $(D P)$ do pulvino. Todas as equações lineares simples, geométricas ou exponenciais permitiram boas estimativas da área foliar e área externa do pecíolo. Do ponto de vista prático, sugerese optar pela equação linear simples envolvendo os respectivos produtos do comprimento pela largura máxima, considerando o coeficiente linear igual a zero. Desse modo, a estimativa da área foliar do limbo $(A F)$ de $E$. crassipes pode ser feita pela fórmula $A F=0,720(C \times L)$; e a área externa do pulvino $(A P)$ pode ser estimada pela fórmula $A P=2,378(C P \times D P)$, com coeficientes de determinação $\left(R^{2}\right)$ de 0,9716 e 0,9268, respectivamente.
\end{abstract}

Palavras-chave: planta aquática, biometria, aguapé.

\begin{abstract}
The objective of this study was to obtain equations that allowed to estimate the leaf area and the float petiole outward area of Eichhornia crassipes, by studying the correlations between true leaf area and leaf dimensional parameters such as leaf length in the mid rib direction $(C)$, and maximum leaf width (L), in the mid rib perpendicular direction, as well as the correlations between true float petiole outward area and maximum length (CP) and the largest transversal diameter (DP) of the float petiole. All the linear, geometric and exponential equations provided good leaf area and float petiole outward area estimates. It is suggested to opt for simple linear equations involving the respective $C \times L$, considering zero as the linear coefficient. Thus, leaf area (AF) of $\mathbf{E}$. crassipes can be estimated by the equation $\mathrm{AF}=0,720(\mathrm{C} x \mathrm{~L})$ and the float petiole outward area (AP) by the equation $A P=2,378$ (CP $\times$ DP), with $R^{2}$ of 0.9716 and 0.9268 , respectively.
\end{abstract}

Key words: aquatic plant, biometry, water hyacinth.

\section{INTRODUÇÃO}

Dentre os fatores que afetam a produtividade econômica de qualquer cultura agrícola, a presença de plantas daninhas infestantes ocupa lugar de destaque, pois, além de elas interferirem, na grande maioria das vezes, negativamente na produção, afetam a qualidade do produto e diminuem a relação receita/custo
(Pitelli, 1985). Do mesmo modo, as plantas daninhas de ambiente aquático também são muito prejudiciais às atividades econômicas do homem, prejudicando a navegação, a pesca e a conservação de tanques ou reservatórios de água. Os maiores problemas são verificados quando da formação de grandes ilhas de vegetação flutuante, que oferecem perigo às tomadas de água das turbinas das barragens, pontes

Recebido para publicação em 6.8.2002 e na forma revisada em 21.10.2002.

2 Eng.-Agr. M.S., Pós-graduado no curso de Produção Vegetal da Faculdade de Ciências Agronômicas - FCAVJ/UNESP. 18.610260 Botucatu-SP; ${ }^{3}$ Prof. Titular do Dep. de Biologia Aplicada à Agropecuária da FCAVJ/UNESP, 14.870-000 Jaboticabal-SP. 
e outras construções marginais. Com relação às usinas hidrelétricas, essas ilhas flutuantes podem exercer grande pressão sobre as barragens e acelerar o processo de assoreamento do lago formado pela usina.

O aguapé (Eichhornia crassipes) é considerado por Holm et al. (1991) a oitava planta daninha de maior expressão mundial, sendo, no Brasil, a mais séria planta daninha aquática flutuante (Lorenzi, 2000). Possui caule curto, com um tufo de raízes finas que chegam a atingir até $60 \mathrm{~cm}$ de comprimento. As folhas do aguapé estão dispostas em roseta, sendo normalmente elipticas ou reniformes. Os pecíolos são esponjosos e, dependendo da circunstância, inflados, o que auxilia na flutuação da planta. Essa estrutura também é denominada pulvino. Tanto o pecíolo quanto o limbo foliar possuem grandes estômatos, que facilitam e contribuem para elevar a taxa de evapotranspiração (Kissmann \& Roth, 1997). Holm et al. (1991) comentam que uma superfície contendo plantas de aguapé pode apresentar uma taxa de evapotranspiração cerca de duas a oito vezes maior do que a mesma superfície livre de plantas. Isso se reveste de fundamental importância nos dias atuais, uma vez que a retenção e conservação de água nos reservatórios têm recebido especial atenção por parte das usinas geradoras de energia elétrica.

Considerando a importância desta planta daninha, há grande necessidade de estudos básicos envolvendo aspectos relacionados a reprodução, crescimento, desenvolvimento, exigências nutricionais, respostas aos sistemas de controle e outros. Na maioria desses estudos, o conhecimento da área foliar é fundamental, sendo uma das características mais difíceis de ser mensuradas, porque normalmente requer equipamentos caros ou utiliza técnica destrutiva, como comentam Bianco et al. (1995). Uma das opções interessantes consiste na utilização de equações que permitam a estimativa da área foliar a partir de medidas lineares da folha. Este método já foi utilizado com sucesso em inúmeras plantas cultivadas e plantas daninhas, como Wissadula subpeltata (Bianco et al., 1983), Senna obtusifolia (Peressin et al., 1984), Solanum americanum (Tofoli et al., 1998) e Panicum maximum (Bianco et al., 2001), entre outras.
O presente trabalho teve o objetivo de determinar uma equação adequada para a estimativa da área foliar e da área externa do pulvino de $E$. crassipes, por intermédio de medidas lineares do limbo foliar e do pulvino, respectivamente.

\section{MATERIAL E MÉTODOS}

Foram coletados 100 limbos foliares, com os respectivos pulvinos de E. crassipes. As plantas encontravam-se em condições naturais de uma represa agrícola, sendo colhidas apenas aquelas que apresentavam bom aspecto sanitário e nutricional. Foram consideradas todas as folhas e seus respectivos pulvinos da planta, descartando-se apenas aquelas que apresentavam deformações decorrentes da ação de agentes externos, como pragas e moléstias.

As plantas foram acondicionadas em caixas plásticas contendo água, as quais foram levadas ao laboratório para obtenção dos valores necessários para a pesquisa. Esse procedimento procurou evitar que a perda de turgidez das folhas pudesse alterar os resultados.

No laboratório, em cada folha foram determinados o comprimento ao longo da nervura principal $(C)$ e a largura máxima perpendicular à nervura principal $(L)$; e em cada pulvino foram determinados o comprimento máximo $(C P)$ e o maior diâmetro transversal $(D P)$. As áreas reais do limbo foliar ( $\mathrm{Sr}$ ) e do pulvino $(\mathrm{APr}$ ) foram obtidas através do aparelho Area Meter li-cor 2000.

Para a determinação de uma equação que representasse a área do limbo foliar e do pulvino procedeu-se a estudos de regressão com equações lineares $(\mathrm{Y}=\mathrm{a}+\mathrm{bx}$ e $\mathrm{Y}=\mathrm{bx})$, geométrica $\left(\mathrm{Y}=\mathrm{ax}^{\mathrm{b}}\right)$ e exponencial $\left(\mathrm{Y}=\mathrm{ab}^{\mathrm{x}}\right)$. $\mathrm{O}$ valor $\mathrm{Y}$ estima a área em função de $\mathrm{x}$, cujos valores podem ser o comprimento $(C$ ou $C P)$, a largura $(L$ ou $D P)$ ou o produto $(C \times L$ ou $C P \times D P)$. No caso de $\mathrm{x}=C \times L$ ou $\mathrm{x}=C P \times D P$, estimou-se também a equação linear passando pela origem, o que praticamente significa supor que a área é proporcional a um retângulo. A equação a ser escolhida será a que apresentar a menor soma de quadrados do resíduo na escala real (sem transformações). 


\section{RESULTADOS E DISCUSSÃO}

As equações obtidas com os respectivos coeficientes de determinação estão apresentadas nas Tabelas 1 e 2 . Pode-se observar que todas as equações de regressão relacionando as áreas reais e os parâmetros dimensionais do comprimento, da largura máxima e do produto entre o comprimento e a largura máxima poderão permitir boas estimativas da área foliar ou da área externa do pulvino desta espécie. No entanto, os maiores valores do coeficiente de determinação e os menores valores do quadrado médio do resíduo foram observados para as regressões lineares simples entre a área foliar real e o produto do comprimento pela largura da folha, bem como entre a área externa do pulvino e o produto do comprimento pelo diâmetro máximo do pulvino.

Do ponto de vista prático, dessas melhores equações, a de mais fácil aplicação é a que envolve o produto do comprimento pela largura máxima do limbo foliar e o produto do comprimento pelo diâmetro transversal máximo do pulvino. Ainda, observa-se que, forçando a passagem da reta pela origem, não houve aumento sensível no valor do erro-padrão da estimativa $(S y . X)$, mesmo porque o valor do coeficiente linear da equação original foi de pequena expressão.

A relação entre os valores observados e os estimados pela equação para o limbo foliar e para o pulvino pode ser observada nas Figuras 1 e 2, respectivamente. Sugere-se que estimativas relativamente simples e precisas da área do limbo foliar de $E$. crassipes podem ser obtidas pela equação $A F=0,720(C \times L)$ e que estimativas da área externa do respectivo pulvino podem ser obtidas pela equação $A P=$ $2,378(C P \times D P)$, com coeficiente de determinação da ordem de 0,9716 e 0,9268, respectivamente.

Tabela 1 - Equações de regressão para estimativa da área foliar de aguapé (Eichhornia crassipes), utilizando medidas lineares do limbo

\begin{tabular}{|l|l|c|c|c|c|}
\hline \multicolumn{1}{|c|}{ Medida $^{1 /}$} & Equação & S.Q. Resíduo & Sy.X & $\mathrm{r}^{2}$ & GL \\
\hline$C$ & $A F^{2 \prime}=-11,785+6,991 C$ & 497,4604 & 2,24 & 0,9278 & 98 \\
$L$ & $A F=-13,584+5,910 L$ & 324,9522 & 1,81 & 0,9535 & 98 \\
$C \times L$ & $A F=1,227+0,718(C \times L)$ & 200,3457 & 1,42 & 0,9716 & 98 \\
$C \times L(0,0)$ & $A F=0,720(C \times L)$ & 221,0771 & 1,42 & 0,9716 & 99 \\
$C$ (geom) & $A F=1,489 \times C^{1,698}$ & 484,9878 & 2,21 & 0,9359 & 98 \\
$L$ (geom) & $A F=0,858 \times L^{1,797}$ & 291,8318 & 1,72 & 0,9689 & 98 \\
$C$ (expon) & $A F=2,912 \times 1,510^{C}$ & 605,9788 & 2,47 & 0,9689 & 98 \\
$L$ (expon) & $A F=2,580 \times 1,421^{L}$ & 363,8768 & 1,92 & 0,9607 & 98 \\
\hline
\end{tabular}

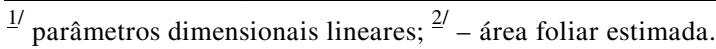

Tabela 2 - Equações de regressão para estimativa da área externa do pulvino de aguapé (Eichhornia crassipes), utilizando medidas lineares do pulvino

\begin{tabular}{|l|l|l|l|l|l|}
\hline Medida $^{1 /}$ & \multicolumn{1}{|c|}{ Equação } & S.Q. Resíduo & Sy.X & $\mathrm{r}^{2}$ & GL \\
\hline$C P$ & $A P^{2 /}=-3,801+7,198 C P$ & 1375,3910 & 3,73 & 0,8917 & 98 \\
$D P$ & $A P=-13,347+16,146 D P$ & 1965,8632 & 4,46 & 0,8409 & 98 \\
$C P \times D P$ & $A P=7,007+1,819(C P \times D P)$ & 946,5611 & 3,09 & 0,9268 & 98 \\
$C P \times P(0,0)$ & $A P=2,378(C P \times D P)$ & 1570,0674 & 3,98 & 0,9268 & 99 \\
$C P($ geom $)$ & $A P=4,742 \times C P^{1,187}$ & 1407,3167 & 3,77 & 0,9123 & 98 \\
$D P($ geom $)$ & $A P=6,405 \times D P^{1,544}$ & 2021,1444 & 4,52 & 0,8546 & 98 \\
$C P($ expon $)$ & $A P=7,812 \times 1,321^{C P}$ & 1913,5031 & 4,40 & 0,8546 & 98 \\
$D P($ expon $)$ & $A P=5,350 \times 1,875^{D P}$ & 2495,6487 & 5,02 & 0,8422 & 98 \\
\hline
\end{tabular}




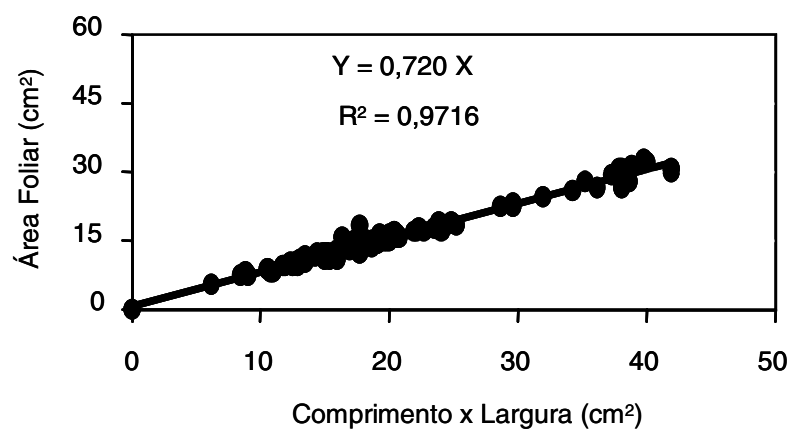

Figura 1 - Valores observados do produto entre o comprimento e largura máxima $(C \times L)$ e a área foliar de Eichhornia crassipes e representação esquemática da equação obtida.

\section{LITERATURA CITADA}

BIANCO, S.; PITELLI, R. A.; PERECIN, D. Método para estimativa da área foliar de plantas daninhas. 2. Wissadula subpeltata (Kuntze) Fries. Planta Daninha, v. 6, n. 1, p. 21-24, 1983.

BIANCO, S. et al. Estimativa da área foliar de plantas daninhas. XIII. Amaranthus retroflexus L. Ecossistema, v. 20, p. 5-9, 1995.

BIANCO, S.; PITELLI, R. A.; PERECIN, D. Estimativa da área foliar de Panicum maximum usando dimensões lineares do limbo foliar. Planta Daninha v. 19, n. 2, p. 217-221, 2001.

HOLM, L. G. et al. The world's worst weeds. Malabar: Krieger Publishing Company, 1991. 609 p.

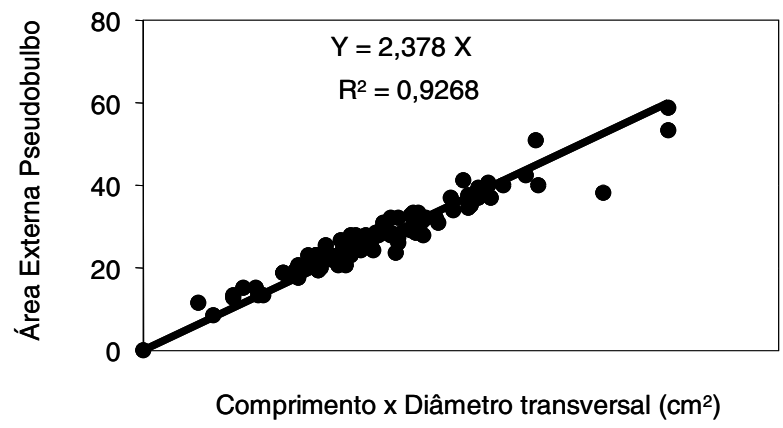

Figura 2 - Valores observados do produto entre o comprimento e diâmetro transversal máximo $(C P \times D P)$ e a área externa do pulvino de Eichhornia crassipes e representação esquemática da equação obtida.

KISSMANN, K.; ROTH, D. Plantas infestantes e nocivas. 2. ed. São Paulo: BASF Brasileira, 1997. T.1. 824 p.

LORENZI, H. Plantas Daninhas do Brasil. 3. ed. Nova Odessa: Instituto Plantarum, 2000. 608 p.

PERESSIN, V.A.; PITELLI, R. A.; PERECIN, D. Métodos para estimativa da área foliar de plantas daninhas. 4. Cassia tora L. Planta Daninha, v. 7, n. 2, p. 48-52, 1984.

PITELLI, R. A. Interferência de plantas daninhas em culturas agrícolas. Inf. Agrop., v. 11, n. 129, p. 16-27, 1985.

TOFOLI, G. R.; BIANCO, S.; PAVANI, M. C. M. D.

Estimativa da área foliar de plantas daninhas: poaia-branca. Planta Daninha, v. 15, n. 1, p. 25-29, 1998. 